\title{
Analysis of the field of specific knowledge of occupational risks related to handling toxic substances
}

\author{
Doru Darabont ${ }^{1}$, Alina Trifu ${ }^{*}$, Daniel Badea ${ }^{1}$, Bogdan Țărnău ${ }^{2}$ \\ ${ }^{1}$ National Institute for Research and Development in Occupational Safety "Alexandru Darabont" - \\ INCDPM, B-dul Ghencea 35A, Bucharest, Romania \\ ${ }^{2}$ SC Medinet HC Services SRL, Arad, Romania
}

\begin{abstract}
This paper presents the findings of an ongoing project developed in collaborations with SC Medinet HC Services SRL that addresses the occupational safety issues related to handling toxic substances, with emphasis on risk identification. INCDPM carried out an extensive literature review of existing published relevant materials, textbooks, journals, conference papers, and internet that were processed with PRISMA method (Preferred Reporting Items for Systematic Reviews and Meta-Analyses) and together with SC Medinet partner that provided an operational study and onsite risk identification, developed an extensive and comprehensive list of occupational risks related to handling toxic substances.
\end{abstract}

\section{Introduction}

Toxic substances pose a wide range of health hazards (such as irritation, sensitization, and carcinogenicity) and physical hazards (such as flammability, corrosion, and explosibility). Toxic materials are substances that may cause harm to an individual if it enters the body. Toxic materials are often used in the workplace.

This paper presents the findings of an ongoing project developed by INCDPM in collaborations with SC Medinet HC Services SRL that addresses the occupational safety issues related to handling toxic substances, with emphasis on pest control domain, because this is main INCDPM's partner activity.

Toxic substances used in pest control activities are pesticides which, according to the Directive 2009/128/EC on the sustainable use of pesticides, are defined as substances used to prevent, destroy, repel, or mitigate any pest ranging from insects, animals, and weeds to microorganisms [1]. Occupational end users of pesticides may experience bodily absorption of the pesticide products they use and this puts them at risk of possible health effects associated with pesticide exposure [2].

\footnotetext{
* Corresponding author: alinatrifu@yahoo.com
} 


\section{Method}

For this paper it was used The Preferred Reporting Items for Systematic reviews and MetaAnalyses (PRISMA). The PRISMA has been designed primarily for systematic reviews of studies that evaluate the effects of health interventions, irrespective of the design of the included studies. However, the checklist items are applicable to reports of systematic reviews evaluating other non-health-related interventions (for example, social or educational interventions), and many items are applicable to systematic reviews with objectives other than evaluating interventions [3]. The PRISMA 2020 items are relevant for mixed-methods systematic reviews (which include quantitative and qualitative studies).

A literature search was conducted in ScienceDirect Freedom Collection, Elsevier database, Web of Science - Core Collection, Clarivate Analytics, Scopus, SpringerLink Journals. Keywords such as toxic substances occupational risk in rodent control, risk assessment for pest control services, pest control job hazard analysis were used to retrieve relevant studies which explicitly reported on occupational risks related to handling toxic substances. The searches were limited to English and Romanian languages only. The PRISMA checklist was used to validate the research process [6].

The titles and abstracts of the search results were screened independently by all authors with discrepancies discussed and resolved.

Articles were eligible for full-text screening if the title and/or abstract mentioned occupational risks in pest control, risk assessment for pest control services, pest control job hazard analysis, in addition to "toxic substances". Full-texts were screened for inclusion by all authors disagreements resolved by discussion. Articles were included in this systematic review if they reported on occupational risks in pest control services. Research studies that made use of previously collected or administrative data were also acceptable if they satisfied other criteria. Studies were excluded if they were published before 2000. 


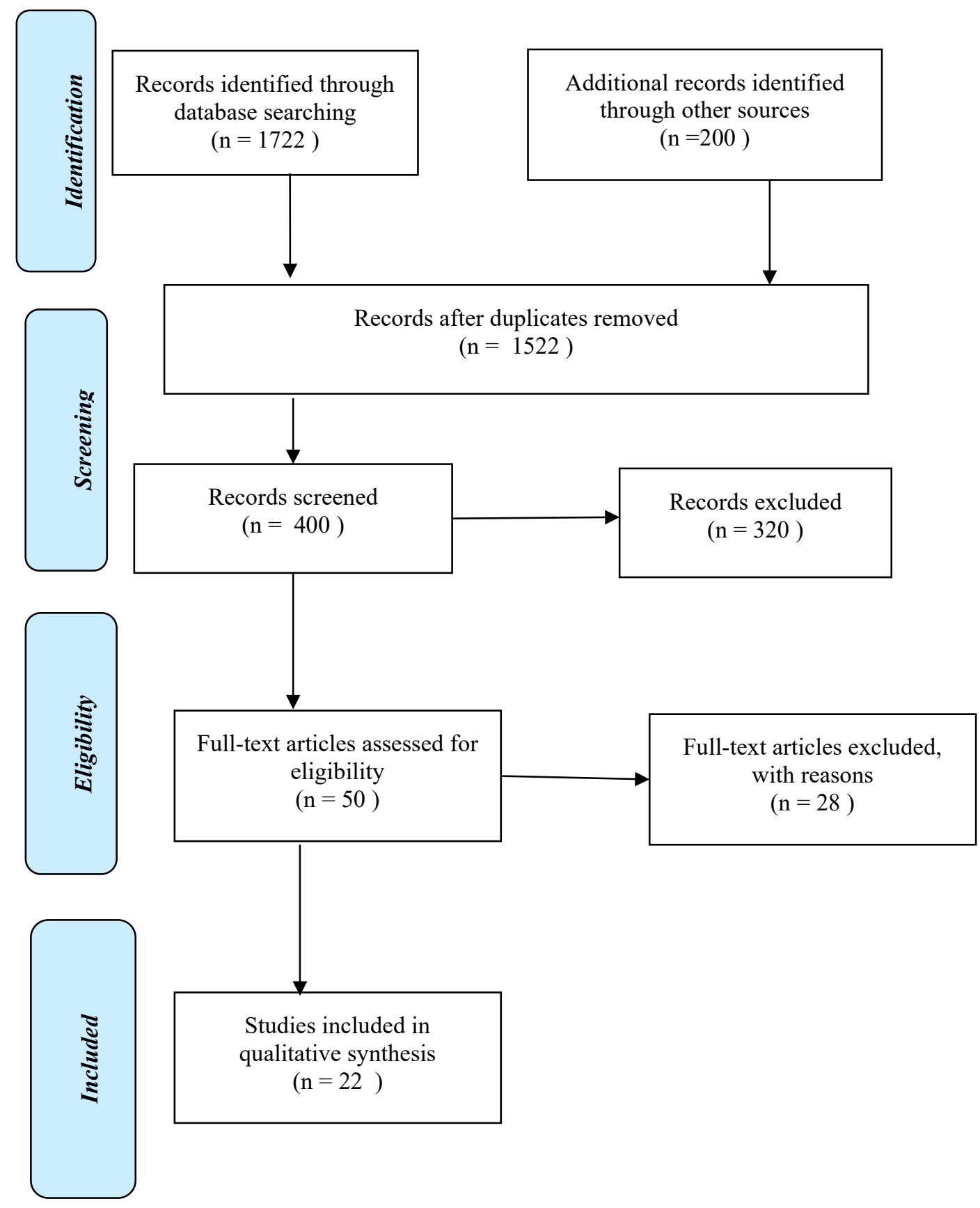

Fig. 1. PRISMA flow diagram 


\section{Results and discussion}

The literature search yielded 1722 references, of which 50 articles were selected for full-text screening as specified by the inclusion criteria, and ultimately 22 were included in this review (Fig. 1).

Operators may be exposed to a pesticide when opening containers, mixing/loading or preparing the product for use, during application of the product, cleaning up spills, maintaining equipment and re-entering treated areas. The main routes of exposure are dermal and inhalation. Risk assessments are carried out for all scenarios of exposure that can be expected to occur through the use of the pesticide. Both acute (immediate) and chronic (longterm) risks need to be considered.

Chemicals (pesticides) used by pest exterminators are usually toxic to man. They may cause acute or chronic poisoning, burns, skin, eyes, throat and other disorders, and be harmful in other ways. Some pesticides are flammable, and their careless handling and storage may cause fires. Pest exterminators often work in uncomfortable postures and handle heavy loads, which may cause traumas and, in the course of time, back, hands and arms pains.

Organophosphate pesticides are widely used to control insect pests. Most organophosphate pesticides are moderately toxic and people failing to follow safe work practices are at risk of absorbing significant quantities of pesticides through the skin or by inhalation. They may be exposed during decanting, mixing of pesticides, spraying or contamination from spillage, spray drift or pesticide residues. Organophosphate pesticides depress serum plasma and red blood cell cholinesterase levels. Prevent poisoning by monitoring workers at risk, so those with depressed cholinesterase activity can be removed from further exposure before serious health effects occur [4].

Chemical pesticides consist of an active ingredient, the actual poison, and a variety of additives, which improve the efficacy of its application and action. Pesticides can be classified or grouped according to the target organisms (e.g., insecticides, fungicides, and herbicides), chemical structure of the compound (e.g., organochlorine, organophosphorus, phenoxy acid herbicides, urea, and pyrethroids) [4], or type of health hazard involved [5].

In the table below we summarised the main occupational risks related to handling toxic substances.

Table 1. Main occupational risks related to handling toxic substances

\begin{tabular}{|c|c|}
\hline $\begin{array}{c}\text { Type of risk } \\
\text { factors }\end{array}$ & Form of manifestation \\
\hline \multirow{7}{*}{ Chemical } & $\begin{array}{c}\text { Severe chronic intoxication due to exposure to pesticides (may result } \\
\text { in disease or death) }\end{array}$ \\
\cline { 2 - 3 } & $\begin{array}{c}\text { Various skin effects (itching, erythema, dermatoses, blistering, } \\
\text { irritation, sensitization, photosensitization, etc.), as a result of } \\
\text { exposure to vapours, spray, and gaseous forms of pesticides }\end{array}$ \\
\cline { 2 - 3 } & $\begin{array}{c}\text { Chloracne and porphyria cutana tarda, due to contact with chlorinated } \\
\text { pesticides }\end{array}$ \\
\cline { 2 - 3 } & $\begin{array}{c}\text { Eye irritation, cataracts, corneal and conjunctival injuries, esp. in } \\
\text { pesticide sprayers }\end{array}$ \\
\cline { 2 - 3 } & $\begin{array}{c}\text { Mouth and throat irritation, burns and ulcers of the mouth in pesticide } \\
\text { sprayers. Various pulmonary diseases, including lung edema, } \\
\text { pneumonitis, asthmatic reactions, alveolitis, pneumoconiosis etc. }\end{array}$ \\
\hline $\begin{array}{c}\text { Various gastro-intestinal effects, including abdominal pains, cramps, } \\
\text { diarrhea, nausea, vertigo, giddiness, headaches, etc. }\end{array}$ \\
\hline
\end{tabular}




\begin{tabular}{|c|c|}
\hline & $\begin{array}{l}\text { Nervous system disorders, including neurotoxicity, postural } \\
\text { instability, neuropathy, neuro-behavioral effects, insomnia, etc. } \\
\text { Effects on blood and circulatory system, caused by exposure to } \\
\text { pesticides, esp. to chlorinated hydrocarbons and organophosphates } \\
\text { Musculoskeletal and soft tissue problems and other systemic effects } \\
\text { Carcinogenic effects, including cancer of bladder, brain, liver, lung, } \\
\text { prostate, gastro- intestinal tract, respiratory system, testicles, } \\
\text { malignant lymphomas, leukemia, multiple myeloma, and other forms } \\
\text { of carcinogenic and mutagenic effects }\end{array}$ \\
\hline \multirow{3}{*}{ Physical } & $\begin{array}{c}\text { Exposure to direct and reflected ultraviolet (solar) radiation while } \\
\text { working outdoors, possibly leading to erythema, skin cancer, } \\
\text { cataracts and photokeratitis }\end{array}$ \\
\hline & $\begin{array}{l}\text { Exposure to harsh climatic conditions, e.g., heat (resulting in effects } \\
\text { ranging from temperature discomfort to heat stroke), high humidity, } \\
\text { cold, etc }\end{array}$ \\
\hline & $\begin{array}{l}\text { Exposure to whole-body vibrations caused by inadequate vehicle } \\
\text { suspension, uncomfortable seat, etc. }\end{array}$ \\
\hline Biological & $\begin{array}{l}\text { Being infected by a zoonotic disease transmitted by rodents, fleas, } \\
\text { mosquitoes, or other insects during extermination work }\end{array}$ \\
\hline \multirow{3}{*}{$\begin{array}{l}\text { Ergonomic, } \\
\text { psychosocial } \\
\text { and } \\
\text { organizational }\end{array}$} & Back pains in hand-spray workers \\
\hline & $\begin{array}{c}\text { Musculoskeletal injuries caused by physical overexertion and } \\
\text { awkward posture while carrying and otherwise handling containers } \\
\text { and heavy pieces of equipment }\end{array}$ \\
\hline & $\begin{array}{l}\text { Tiredness and general ill feeling Psychological stress resulting from } \\
\text { the fears of potential overexposure to pesticides and of failing the } \\
\text { compulsory periodical health check-ups }\end{array}$ \\
\hline
\end{tabular}

Also, from the literature reviewed we extracted the most common accidents that can occur during handling substances:

- Contamination of exterminators during the mixing of concentrated hazardous pesticides

- Acute poisoning while applying pesticides (esp. as a result of inhaling aerosols while not wearing protective mask; could be fatal), or as a result of spills and fires during transportation and storage of pesticides

- Skin contact or ingestion of pesticides due to contamination, splashing, or spills, esp. during preparation, mixing and filling operations

- Accidental inhalation of pesticide spray (caused by a sudden change of wind, or by a poorly selected and maintained protective mask, etc.)

- Risk of accidental swallowing of a liquid pesticide mistakenly thought to be water, or of pesticide-polluted irrigation water

- Bursting of over pressurized spraying vessels, resulting in pesticide splashes capable of hitting the operator

- Acute intoxication as a result of release into the atmosphere of hazardous compounds (e.g., $\mathrm{HCN}, \mathrm{SO} 2, \mathrm{NOx}$ ) during accidental (fires or explosions) or intentional (owing to poor judgment) burning of pesticides or pesticide containers

- Electric shocks caused by contact with defective electromechanical equipment

- Falls from elevated platforms, roofs and stairs, esp. while carrying containers and other heavy loads

- The slips, trips, falls and bumps (on slippery surfaces and at obstacles, esp. while wearing protective mask limiting the field of vision) Falls of heavy loads, esp. containers, on workers' feet 
- Risk of getting hernia as a result of overstrenous movements when lifting and loading heavy loads

- Increased risk of road accidents due to lengthy periods of driving heavily loaded vehicles, incl. towing trailers and mechanical spraying equipment, on field roads

- Stabs and cuts caused by sharp objects Bites and stings by rodents, insects, etc. Fire hazard due to careless storage of flammable pesticides

\section{Conclusions}

Operators may be exposed to a pesticide when opening containers, mixing/loading or preparing the product for use, during application of the product, cleaning up spills, maintaining equipment and re-entering treated areas. The main routes of exposure are dermal and inhalation. Risk assessments are carried out for all scenarios of exposure that can be expected to occur through the use of the pesticide. Both acute (immediate) and chronic (longterm) risks need to be considered. Risk with the use of the pesticide product can be mitigated through engineering controls (such as closed application systems) and/or personal protective equipment (such as gloves or respirators). Chemicals (pesticides) used by pest exterminators are usually toxic to man. They may cause acute or chronic poisoning, burns, skin, eyes, throat and other disorders, and be harmful in other ways. Some pesticides are flammable, and their careless handling and storage may cause fires. Pest exterminators often work in uncomfortable postures and handle heavy loads, which may cause traumas and, in the course of time, back, hands and arms pains.

The results presented in this paper are partial results from the project „Partnership for knowledge transfer and research development related to the assessment and prevention of occupational risks that can lead to disasters (PROC)", ID / SMIS Code 2014+: POC P_40_182 / 111954, Subsidiary contract no. 5/08.03.2021 SC Medinet HC Services SRL.

\section{References}

1. European Agency for Safety and Health at Work (1996) Guidance on risk assessment at work (Directive 89/391/EEC). https://osha.europa.eu/en/topics/riskassessment/guidance.pdf

2. European Agency for Safety and Health at Work (EU-OSHA). Dangerous substances (excluding biological agents), https:/osha.europa.eu/en/sector/agriculture/ds/\#legislation, Accessed at 06/01/2021

3. MJ. Page, JE McKenzie, PM Bossuyt, I Boutron, TC Hoffmann, CD Mulrow, et al, Prisma systematic Reviews (open access). The PRISMA 2020 statement: an updated guideline for reporting systematic reviews. Systematic Reviews 2021;10:89

4. OSH in the pest control industry, available on www.worksafe.wa.gov.au

5. E. MacFarlane, R. Carey, T. Keegel, S. El-Zaemay, L. Fritschi, Dermal Exposure Associated with Occupational End Use of Pesticides and the Role of Protective Measures, Safety and Health at Work Volume 4, Issue 3, September 2013, Pages 136-141

6. MJ. Page, JE McKenzie, PM Bossuyt, I Boutron, TC Hoffmann, CD Mulrow, et al. Systematic Reviews (open access), The PRISMA checklist 